\title{
Basis of a finite-element simulation tool to predict the flexural behaviour of SFRC prisms
}

\author{
T. Soetens (1), S. Matthys (1), L. Taerwe (1), A. Van Gysel (2)
}

(1) Magnel Laboratory for Concrete Research, Department of Structural Engineering, Faculty of Engineering and Architecture, Ghent University, Ghent, Belgium

(2) Campus De Nayer, Materials and Structures Research Group, Department of Applied Engineering, Lessius University College Mechelen, Belgium

\begin{abstract}
The fibre pull-out response of a steel fibre, both straight and endhooked, embedded in a concrete matrix has been widely investigated in the past. Attention was given to the influence of the type of fibre, the concrete strength and the inclination of the pull-out force. Hooked-end fibres need more energy to be pulled out of the concrete and thus are preferably used in steel fibre reinforced concrete (SFRC) for structural purposes.

Based on this single fibre pull-out behaviour, numerous analytical and numerical methods were verified with experimental results of three- or four-point bending tests on small prisms. In this paper, a new approach to characterize the nonlinear bending behaviour of steel fibre reinforced concrete is proposed. Finite element (FE) analyses were conducted on a small prism-model, containing randomly generated small embedded reinforcement elements, which material properties are based on the pull-out behaviour derived from earlier research activities. In this stage, attention was also given to the orientation of the fibres.

Eventually, a good correlation was found between the numerical and experimental results and the fine-tuned model was then used to perform a large number of numerical bending tests. In that way, the scatter of the parameters that describe the non-linear bending behaviour of small steel fibre reinforced concrete prisms was estimated in a much faster way than by experimental testing. These parameters are usually needed to evaluate the structural behaviour of SFRC elements according to current design guidelines for SFRC.
\end{abstract}

\section{Introduction}

In the past three decades, many researchers studied the single fibre pull-out response of a fibre embedded in a cementitious matrix. This research led to the development of several pull-out models to describe the pull-out response of both straight [1, 2] and hooked-end [3-8] fibres. Accurate predictions of the pull-out response served as a basis to develop computational models to characterize the behaviour of SFRC subjected to pure bending or uni-axial tension. This characteriza- 
tion, in particular the bending behaviour of small prisms either by three- or fourpoint bending tests, is very important to derive parameters that are used in current design guidelines for SFRC [9].

In this paper a new approach to estimate flexural toughness parameters is explained. The pull-out response of a single fibre was used to generate different samples of a FE-model with randomly distributed fibres and results from both experimental and numerical analyses are compared and discussed.

\section{Experimental testing}

\subsection{Test setup}

Four small prisms with a span length $l$ of $450 \mathrm{~mm}$ were subjected to a four-point bending test with the test setup in accordance with the Belgian standard NBN B15-238 (1992). The prisms have a square cross section with a height $h$ of $150 \mathrm{~mm}$ and the total length is equal to $600 \mathrm{~mm} .40 \mathrm{~kg} / \mathrm{m}^{3}$ of DRAMIX ${ }^{\circledR}$ fibres, type ZC 60/.80 HC, were added to the concrete, which general characteristics are showed in Table 1 . To achieve a load-deflection curve which can quantify the post-peak behaviour of the prism, a displacement controlled test was necessary.

Table 1. Main properties of the used concrete

\begin{tabular}{ll}
\hline \multicolumn{2}{c}{ Concrete characteristics } \\
\hline Mean compression strength $f_{c m}$ & $90.3 \mathrm{~N} / \mathrm{mm}^{2}$ \\
Mean tensile strength $f_{c t m}$ & $4.89 \mathrm{~N} / \mathrm{mm}^{2}$ \\
Modulus of elasticity $E$ & $45800 \mathrm{~N} / \mathrm{mm}^{2}$ \\
Fracture Energy $G_{f}$ & $163 \mathrm{~N} / \mathrm{m}$ \\
W/C ratio & 0.30 \\
\hline
\end{tabular}

\subsection{Characterization of the flexural toughness}

Flexural toughness can be quantified in two different ways as stated in the Belgian standard. According to the first method, the ratio $D_{n}$ between the applied load $F_{n}$ at a certain deflection $l / n$ (i.e. $l / 600, l / 450, l / 300$ and $l / 150$ ) and the force $F_{r}$ when cracking occurs, is calculated. The second method defines the flexural toughness as the surface $B_{n}$ beneath the load-deflection curve until a prescribed deflection (i.e. $l / 300$ and $l / 150$ ) is reached. The conventional flexural strength is denoted as $f_{f, n}$ and is given by equation (1).

$f_{f, n}=\frac{B_{n} n}{b h^{2}}$ 
All values of $D_{n}$ and $f_{f, n}$, derived from four experimental four-point bending tests, performed by Van Gysel, are summarized in Table 2. These values were derived from the load-deflection curves (solid black lines) displayed in Fig. 2.

Table 2. Parameters to characterize the flexural toughness of SFRC

\begin{tabular}{ccccccc}
\hline Prism nr. & $D_{600}[-]$ & $D_{450}[-]$ & $D_{300}[-]$ & $D_{150}[-]$ & $f_{f, 300}[\mathrm{MPa}]$ & $f_{f, 150}[\mathrm{MPa}]$ \\
\hline 1 & 1.39 & 1.44 & 1.37 & 1.09 & 7.03 & 6.93 \\
$2 *$ & - & - & - & - & - & - \\
3 & 1.37 & 1.36 & 1.16 & - & 6.39 & - \\
4 & 1.18 & 1.15 & 1.06 & 0.74 & 6.69 & 4.92 \\
Mean & 1.31 & 1.32 & 1.20 & 0.92 & 6.70 & 5.93 \\
\hline
\end{tabular}

* failure at a central deflection of about $0.75 \mathrm{~mm}$.

Regarding the values of Table 2, a general remark should be made: although all four-point bending were precisely executed as described in the Belgian standard, the results were not sufficient for all prisms to determine the flexural toughness indices. Without guarantee in advance of achieving useful test results, a significant number of tests is needed to determine the scatter of flexural toughness parameters of SFRC.

\section{Numerical analysis}

To avoid time-consuming test procedures and to assure a useful load-deflection curve, a solution of the problem stated earlier can be found through numerical simulations. By the continuous improvement of computer hardware, computation times of complex numerical problems are reduced in a very fast way and new approaches to elaborate a finite element simulation tool for SFRC has become feasible: it takes about 3 hours $^{1}$ to perform a complete non-linear analysis with the software program Atena Science ${ }^{2}$.

\subsection{FE-model}

Due to the three dimensional distribution of fibres within a prescribed volume, an accurate simulation cannot be obtained by a much simpler two-dimensional numerical model and thus the whole prism was divided in tetrahedral (i.e. 3D solid) quadratic elements with a size of $15 \mathrm{~mm}$, representing the coarseness of the concrete matrix. In the crack model, the option 'rotating' was chosen and a crack bandwidth of $15 \mathrm{~mm}$ was assumed. A simulated specimen without fibres was used to calibrate the input parameters for concrete. It followed that a small adaptation

${ }^{1}$ Duration of a single analysis with one central processing unit of 2,67 Ghz

${ }^{2}$ AtenaWin v4 Statics module, developed by Cervenka Consulting 
of the input tensile strength and fracture energy, with respect to the values given in Table 1, was necessary.

\subsection{Distribution of fibres}

When adding $40 \mathrm{~kg} / \mathrm{m}^{3}$ of DRAMIX ${ }^{\circledR} \mathrm{ZC} 60 / .80 \mathrm{HC}$ fibres to a prism with a volume of 150 x 150 x $600 \mathrm{~mm}^{3}$, about 2280 fibres should be drawn as a straight line. Considering this to be impossible to do by hand, a small software program was developed that reads all input data from the calculation file of Atena and adds an amount of fibres automatically, based on fibre properties and the shape of the volume (i.e. a rectangular prism). This volume is formed by a cross-section in a $y z-$ plane that is extruded along the $x$-axis, in the longitudinal direction of the prism.

Although the main objective of the program is to add fibres in a volume in such way that the distribution of fibres approaches the real configuration, the presence of coarse aggregates was not taken into account at this stage. The orientation of a single fibre is represented by the angle $\theta$ with respect to the longitudinal axis $x$ of the prism (i.e. the $x$-axis). Based on the experimental investigation of Laranjeira et al. [10], a Gaussian distribution was assumed for the orientation angle $\theta$, which is defined by an orientation number $\eta_{\theta}$, given by (2).

$\eta_{\theta}=\frac{1}{N} \sum_{i=1}^{N} \cos \theta_{i}$

The average $\theta_{m}$ and standard variation $\sigma_{(\theta)}$, both in radians, of the normal distribution can be calculated by equations (3) and (4).

$\theta_{m}=\arccos \left(\eta_{\theta}\right)$

$\sigma(\theta)=\frac{\pi}{2} \eta_{\theta}\left(1-\eta_{\theta}\right)$

A second objective was to implement the pull-out model for hooked-end fibres developed by Van Gysel [8]. The pull-out response is mainly affected by the inclination of the pull-out force and the embedded length. So, for each fibre within the concrete volume a unique load-slip diagram exists, but implementing this would lead to a too complex model. To solve this problem, both the range of orientation angles and the embedded lengths are divided in discrete intervals.

In this way, the orientation angle $\theta$ is divided in six intervals from 0 to 90 degrees and each orientation angle interval is divided in another six sub-intervals going from $5 \mathrm{~mm}$ to half the fibre length, with an interval width of $5 \mathrm{~mm}$. The discretization matrix for such a division is displayed in Table 3. 
Table 3. Discretization matrix and corresponding material numbers

\begin{tabular}{ccccccc}
\hline & \multicolumn{5}{c}{ Embedded length $l_{f}$} \\
\hline Orientation interval $\left[^{\circ}\right]$ & $5 \mathrm{~mm}$ & $10 \mathrm{~mm}$ & $15 \mathrm{~mm}$ & $20 \mathrm{~mm}$ & $25 \mathrm{~mm}$ & $30 \mathrm{~mm}$ \\
{$[0 ; 7.5]$} & 1 & 2 & 3 & 4 & 5 & 6 \\
{$[7.5 ; 22.5]$} & 7 & 8 & 9 & 10 & 11 & 12 \\
{$[22.5 ; 37.5]$} & 13 & 14 & 15 & 16 & 17 & 18 \\
{$[37.5 ; 52.5]$} & 19 & 20 & 21 & 22 & 23 & 24 \\
{$[52.5 ; 67.5]$} & 25 & 26 & 27 & 28 & 29 & 30 \\
{$[67.5 ; 90]$} & 31 & 32 & 33 & 34 & 35 & 36 \\
\hline
\end{tabular}

Thus, when sampling a specimen that includes fibres, each fibre is linked to a material number between 1 and 36 within the FE-model, taking into account the normal distribution of the orientation angle $\theta$ and a uniform distribution of the embedded length $l_{f}$.

To model the pull-out response of a fibre, an equivalent stress-strain diagram was defined based on a load-slip diagram. The equivalent strain $\varepsilon_{e q}$ is calculated as the ratio between the slip $s$ and the total length of the fibre $l_{\text {tot }}$ and the equivalent stress as the ratio between the pull-out-force $F_{u}$ and the cross-section of the fibre $A_{f}$. As a result of this approach, cable elements were needed to assure that a constant stress would appear over the whole length of the fibre when a strain was locally induced due to crack formation. Fig. 1 shows a sampled FE-model with fibres.

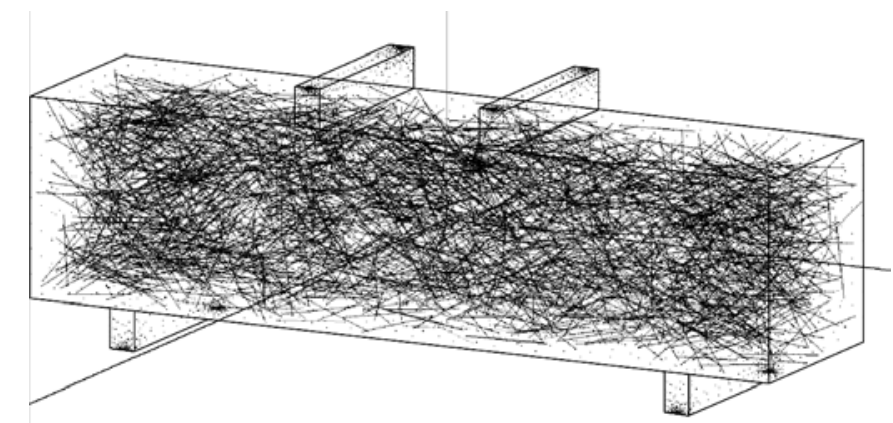

Fig. 1. Sampled FE-model of a prism containing fibres

Three series of FE-models, each with different orientation number $\eta_{\theta}(0.80,0.75$ and 0.70 ), were analysed and the resulting load-deflection diagrams where then used to derive the flexural toughness parameters $D_{n}$ and $f_{f, n}$.

\section{Results}

Thirty different SFRC prisms were sampled with the software tool and analysed with Atena. All load-deflection curves are displayed in Fig. 2. 


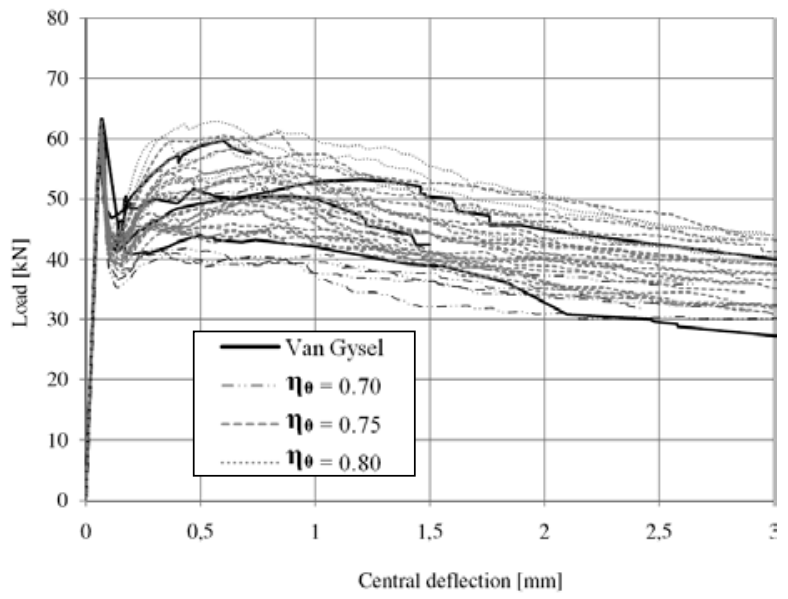

Fig. 2. Load deflection curves as a function of the orientation number $\eta_{\theta}$

When an orientation number of 0.80 ( 5 simulations) was assumed, a systematic overestimating of residual strength occurred, while an orientation number of 0.70 (5 simulations) appears to be too conservative. A good correlation with the experimental results of the four-point bending tests by Van Gysel [8] was found with $\eta_{\theta}$ equal to 0.75 . All results, according to an orientation number of 0.75 (20 simulations), are summarized in Table 4.

Table 4. Flexural toughness parameters for $\eta_{\theta}=0.75$

\begin{tabular}{ccccccc}
\hline Prism nr. & $D_{600}[-]$ & $D_{450}[-]$ & $D_{300}[-]$ & $D_{150}[-]$ & $f_{f, 300}[\mathrm{MPa}]$ & $f_{f, 150}[\mathrm{MPa}]$ \\
\hline 1 & 1.52 & 1.42 & 1.26 & 1.07 & 6.79 & 6.16 \\
2 & 1.24 & 1.16 & 1.12 & 0.88 & 5.77 & 5.28 \\
3 & 1.43 & 1.30 & 1.12 & 0.88 & 6.36 & 5.52 \\
4 & 1.43 & 1.42 & 1.32 & $*$ & 6.52 & $*$ \\
5 & 1.37 & 1.37 & 1.21 & $*$ & 6.21 & $*$ \\
6 & 1.49 & 1.43 & 1.27 & 1.12 & 6.73 & 6.32 \\
7 & 1.21 & 1.19 & 1.10 & 0.98 & 5.87 & 5.35 \\
8 & 1.21 & 1.15 & 1.08 & 0.87 & 5.77 & 5.15 \\
9 & 1.30 & 1.27 & 1.21 & 0.96 & 6.11 & 5.65 \\
10 & 1.36 & 1.34 & 1.21 & 1.07 & 6.27 & 5.9 \\
11 & 0.13 & 0.13 & 1.08 & $*$ & 5.81 & $*$ \\
12 & 1.31 & 1.19 & 1.06 & 0.84 & 5.92 & 5.25 \\
13 & 1.57 & 1.46 & 1.32 & $*$ & 7.04 & $*$ \\
14 & 1.22 & 1.19 & 1.10 & 0.94 & 5.8 & 5.23 \\
15 & 1.46 & 1.31 & 1.09 & $*$ & 6.42 & $*$ \\
16 & 1.63 & 1.51 & 1.37 & 1.18 & 7.29 & 6.46 \\
17 & 1.56 & 1.57 & 1.43 & 1.18 & 7.33 & 6.81 \\
18 & 1.46 & 1.37 & 1.27 & 1.03 & 6.66 & 6.13 \\
19 & 1.33 & 1.32 & 1.21 & 1.00 & 6.47 & 5.89 \\
20 & 1.35 & 1.23 & 1.12 & 1.02 & 6.01 & 5.6 \\
Average & 1.33 & 1.27 & 1.20 & 1.00 & 6.36 & 5.78 \\
Std. Dev. & 0.31 & 0.29 & 0.11 & 0.11 & 0.50 & 0.51 \\
C.O.V. & $23 \%$ & $23 \%$ & $9 \%$ & $11 \%$ & $8 \%$ & $9 \%$ \\
\hline
\end{tabular}


The mean values of the experimental results (Table 2) and the simulated tests (Table 3) are in good agreement.

\section{Conclusions}

Finite-element simulations with randomly distributed embedded cable elements, representing steel fibres, were able to predict the bending behaviour of small steel fibre reinforced concrete prisms used to perform four-point bending tests according to the Belgian standard NBN B15-238 (1992).

Three different orientation numbers were compared to each other and the following conclusion can be made: the proper orientation number for a small prism subjected to bending should be in a range between 0.70 and 0.80 .

Eventually, a good correlation was found for about twenty samples with an orientation number equal to 0.75 and the scatter of the flexural toughness parameter $D_{n}$ and $f_{f, n}$ could be estimated accurately. For the values of $D_{600}$ and $D_{450}$, a coefficient of variation equal to $23 \%$ was found and for the values $D_{300}, D_{150}, f_{f, 300}$ and $f_{f, 150}$ the coefficient of variation was around $9 \%$. This scatter is inherent to the randomness of the fibre position and orientation.

\section{References}

[1] Naaman A.E., Shah S.P., (1976), 'Pull-out Mechanism in Steel Fiber-Reinforced Concrete', Proc. ASCE, Journal of the Structural Division, Vol 102, ST 8, pp 1537-1548.

[2] Stang H., Li Z., Shah S.P., (1990), 'Pull-out Problem: Stress versus Fracture Mechanical Approach', Journal of Engineering Mechanics, ASCE, Vol 116, n 10, pp 2136-2150.

[3] Van Gysel, A., (1999), 'A pullout model for hooked end steel fibres', $3{ }^{\text {th }}$ RILEM workshop on HPFRCC (eds. H. W. Reinhardt and A. E. Naaman), pp. 351-359

[4] Taerwe, L., Van Gysel, A., (1996), 'Influence of steel fibres on design stress-strain curve for high-strength concrete'. In : ASCE Journal of Engineering Mechanics, Aug. 1996, Vol. 122, No. 8, pp. 695-704.

[5] Stroeven P., de Haan Y.M., Bouter C., Shah S.P., (1978), 'Pull-out Tests of Steel Fibres', Testing and Test Methods of Fiber Cement Composites (ed. R.N. Swamy), The Construction Press, UK, pp 345-353.

[6] Chanvillard G., Aïtcin P.-C., (1992), 'On the Modelling of the Pull-out Behaviour of Steel Fibers', High Performance Fiber Reinforced Cement Composites (eds. H.W. Reinhardt en A.E. Naaman), RILEM Proceedings 15, E \& FN Spon, London, pp 388-406.

[7] Naaman A.E., Najm H., (1991), 'Bond-Slip Mechanisms of Steel Fibers in Concrete', ACI Materials Journal, Vol 88, $n^{\circ}$ 2, pp 135-145.

[8] Van Gysel, A., (2000), 'Studie van het uittrekgedrag van staalvezels ingebed in een cementgebonden matrix met toepasing op staalvezelbeton onderworpen aan buiging' (in Dutch), PhD thesis, Magnel Laboratory for concrete research, Ghent University, Belgium.

[9] Jansson, A., (2007) 'Analysis and design methods for fibre reinforced concrete: a state-ofthe-art report.', Dep. of Civil \& Environmental Engineering, Div. of Structural Engineering/Concrete structures, Chalmers University of Technology, 2007:16, Göteborg, 196.pp. 
[10] Laranjeira, F., Grünewald, S., Walraven J., et al., (2010), 'Characterization of the orientation profile of steel fiber reinforced concrete', Materials and Structures, RILEM, November 2010, pp 1-19. 